\title{
A Bidirectional GaN-Based CLLC Converter for Plug-In Electric Vehicles On-Board Chargers
}

\section{Ammar, Ahmed Morsi; Ali, Kawsar ; Rogers, Daniel J.}

\section{Published in:}

Proceedings of $46<$ sup $>$ th $</$ sup $>$ Annual Conference of the IEEE Industrial Electronics Society

Link to article, DOI:

10.1109/IECON43393.2020.9254560

Publication date:

2021

Document Version

Peer reviewed version

Link back to DTU Orbit

Citation (APA):

Ammar, A. M., Ali, K., \& Rogers, D. J. (2021). A Bidikectional GaN-Based CLLC Converter for Plug-In Electric Vehicles On-Board Chargers. In Proceedings of 46 Annual Conference of the IEEE Industrial Electronics Society IEEE. https://doi.org/10.1109/IECON43393.2020.9254560

\section{General rights}

Copyright and moral rights for the publications made accessible in the public portal are retained by the authors and/or other copyright owners and it is a condition of accessing publications that users recognise and abide by the legal requirements associated with these rights.

- Users may download and print one copy of any publication from the public portal for the purpose of private study or research.

- You may not further distribute the material or use it for any profit-making activity or commercial gain

- You may freely distribute the URL identifying the publication in the public portal 


\section{A Bidirectional GaN-Based CLLC Converter for Plug-In Electric Vehicles On-Board Chargers}

\author{
Ahmed M. Ammar \\ Department of Electrical Engineering \\ Technical University of Denmark \\ Kongens Lyngby, Denmark \\ ammma@elektro.dtu.dk
}

\author{
Kawsar Ali and Daniel J. Rogers \\ Department of Engineering Science \\ University of Oxford \\ Oxford, United Kingdom \\ \{kawsar.ali, dan.rogers\}@eng.ox.ac.uk
}

\begin{abstract}
This paper presents a bidirectional CLLC converter solution for the dc-de stage in plug-in electric vehicle (PEV) onboard battery chargers. The proposed architecture allows the converter to operate at resonance for the bidirectional constantpower (CP) load range with a variable bus voltage, while frequency modulation is employed for the constant-current $(\mathrm{CC})$ load range in the grid-to-vehicle (G2V) mode with a fixed bus voltage, resulting in a limited bus voltage range. This enables the use of 650-V Gallium nitride (GaN) devices for the primary and secondary sides' switches. The design flow is presented and a 1$\mathrm{kW}$ high-frequency prototype is implemented. GaN reverse conduction characteristics are investigated and employed for the high-frequency current rectification. The prototype operates with soft switching across the operational range, achieving an efficiency of up to $95.7 \%$, with the resonant inductances integrated in the transformer.
\end{abstract}

Keywords-Electric vehicles, dc-dc converters, resonant power conversion, wide bandgap semiconductors, bidirectional converters

\section{INTRODUCTION}

As the world is moving towards green energy as a replacement for the traditional fossil-fuel-based systems, electric vehicle (EV) technology is advancing, with a rapidly growing market. Plug-in electric vehicles (PEVs), which include plug-in hybrid electric vehicles (PHEVs) and battery electric vehicles (BEVs), are gaining wider adoption, thanks to their efficient energy utilization and reduced combustion emission. In addition, with the recent advancements in the smart-grid technology, bidirectional power flow in PEV battery chargers is necessary to provide the vehicle-to-grid (V2G) support. V2G helps support the grid during voltage sags and frequency dips, especially given the higher dependence of the grid on renewable energy sources. In addition, bidirectional chargers enable consumers to use their EV stored energy for local consumption during power outages, as in the vehicle-to-home (V2H) and vehicle-to-load (V2L) technologies (together with V2G, these are referred to as V2x [1]). Accordingly, new technologies in PEV charger systems are needed to cope with the demand for lightweight, small size, and efficient PEV on-board chargers.

Wide bandgap (WBG) semiconductors technology has greatly evolved and can currently offer many advantages over silicon devices, including much better figures of merit and reduced reverse recovery charge [2]. That has allowed designers to push operational frequencies higher, resulting in higher power densities. For applications with requirements for high efficiency, and at a high switching frequency, soft-switching topologies can help make the most of WBG devices through the elimination of switch turn-on losses.

The conventional architecture of a PEV battery charging system is a two-stage solution, as shown in Fig. 1. A front-end ac-dc converter rectifies the grid voltage and provides power factor correction (PFC), and a following dc-dc stage regulates the intermediate bus voltage into the respective load voltage/current based on the battery state-of-charge (SoC). While the bridgeless totem-pole boost is commonly used for the first stage, two common topologies for dc-dc stage are the phaseshifted full-bridge converter, and the dual active bridge (DAB) converter [3]. However, with the wide output voltage range of state-of-the-art battery technologies, both topologies are limited with respect to the load range for which zero-voltage switching (ZVS) is achieved. On the other hand, the $L L C$ converter can achieve ZVS under any load conditions, making it a good candidate for servers and telecom applications [4]. Nevertheless, it is incapable of the reverse power flow necessary in bidirectional applications with its asymmetric resonant tank [5].

This paper presents a bidirectional CLLC resonant converter for the dc-dc stage in modular level-2 on-board chargers. The operation is similar to the conventional $L L C$ converter, with an added $L C$ tank on the secondary side of the transformer [6], [7]. A variable dc-bus voltage allows the converter to operate at resonance for the entirety of the bidirectional mode, whereas switching frequency modulation is employed for the low battery voltage range in the grid-to-vehicle $(\mathrm{G} 2 \mathrm{~V})$ mode, resulting in a reduced dc-bus voltage range. That, in turn, allows for the use of $650-\mathrm{V} \mathrm{GaN}$ devices for both the primary and secondary sides' switches. A 1-kW high-frequency prototype is designed and implemented. The prototype operates the rectifying devices in reverse conduction and the associated loss is quantified. The high-frequency transformer integrates the resonant tank series inductances, reducing the component count and allowing for high power density.

This paper is organized as follows. Section II shows the system architecture of the proposed converter. Converter design and implementation procedure is presented in Section III. Section IV shows the experimental results of the implemented prototype. Conclusion is then provided in Section V.

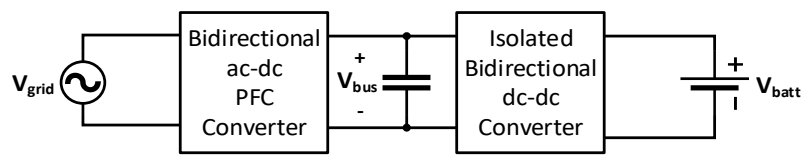

Fig. 1. Conventional PEV charger system architecture. 


\section{SYSTEM ARCHITECTURE}

\section{A. Variable bus voltage}

A typical $400-\mathrm{V}$ EV propulsion battery pack has a terminal voltage of around $250 \mathrm{~V}$ at the lowest SoC, which increases to $450 \mathrm{~V}$ at the highest SoC along the battery charging profile. The fast charging profile consists of two modes [8]. A constantcurrent (CC) mode for the battery voltage range of $250 \mathrm{~V}$ to 320 $\mathrm{V}$, and a constant-power (CP) mode for the range between 320 $\mathrm{V}$ and $450 \mathrm{~V}$. The battery discharge operation in V2G mode is only applicable for the CP range as the battery stops delivering power when its voltage reaches $320 \mathrm{~V}$. While a fixed bus voltage is typical in two-stage systems, it would require the dcdc stage to transform a fixed $V_{b u s}$ to the widely varying battery voltage. In the case of resonant converters, which operate most efficiently at the resonant frequency, the overall system efficiency would be compromised with operation below and above resonance to provide the needed voltage gain. Accordingly, prior art reported a varying $V_{b u s}$ voltage to enable the resonant dc-dc stage to work largely or entirely at resonance [9], with a unity voltage gain, which achieves the optimal efficiency for the dc-dc stage. The tradeoff in that case is the requirement for high-voltage (1000-1200 V) silicon ( $\mathrm{Si}$ ) or silicon carbide ( $\mathrm{SiC}$ ) switches for the primary side devices in the dc-dc stage, in addition to the PFC stage switches.

In this work, a limited bus voltage range is used as the input for the dc-dc stage. Fig. 2 illustrates the bus and battery voltage ranges with the converter modes of operation, where $f_{s}$ and $f_{r}$ are the switching and resonant frequencies, respectively. The converter is designed to operate at resonance, with unity voltage gain, for the entirety of the CP load mode. This eliminates the contribution of the resonant tank voltage gain to the overall converter voltage gain, which is provided through the transformer turns-ratio $n$, thus ensuring symmetry for bidirectional operation. With a minimum $V_{b u s}$ voltage of $380 \mathrm{~V}$, which is the minimum output voltage of a conventional boost/totem-pole converter operating from universal mains input, the required turns-ratio is calculated by

$$
n=\frac{V_{\text {bus_min }}}{V_{C P_{\_} \text {min }}}=1.19,
$$

where $V_{C P_{\text {min }}}$ is the minimum battery voltage for the CP load mode ( $320 \mathrm{~V}$ in the defined charging profile). Designing for a turns-ratio of 1.2, the minimum and maximum voltages for $V_{b u s}$ are calculated to 384 and $540 \mathrm{~V}$, as shown in Fig. 2. For the CC load range, switching frequency modulation is applied on the minimum input voltage of $380 \mathrm{~V}$, where the resonant tank provides additional step-down voltage gain on top of the transformer turns-ratio in order to deliver the battery terminal voltage of $320 \mathrm{~V}$ down to $250 \mathrm{~V}$.

Although the converter operation is not entirely at resonance as in [9], high efficiency can still be achieved as the converter operates at resonance for the entire CP load range, with a reduced frequency modulation operation for the $\mathrm{CC}$ load range. At the same time, the need for boost gain in the resonant tank is eliminated, which simplifies the tank design, especially with respect to the magnetic devices. Critically, the reduced $V_{\text {bus }}$

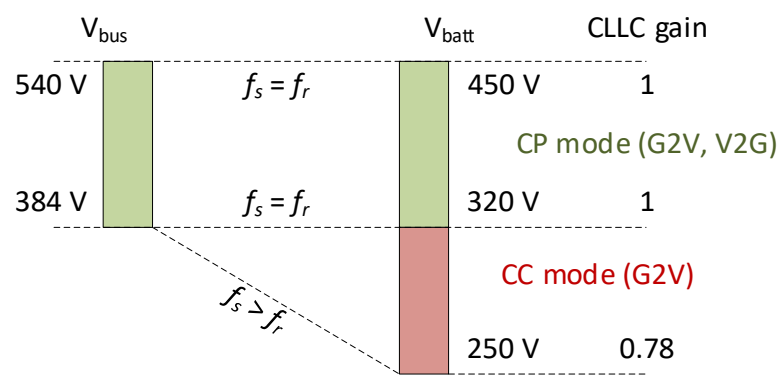

Fig. 2. Converter modes of operation with the presented architecture.

TABLE I. COMPARISON OF PRIMARY SIDE DEVICES WITH THE SAME CURRENT RATING (30 A) IN REPORTED AND PROPOSED ARCHITECTURES

\begin{tabular}{c|c|c|c}
\hline Application & {$[8]$} & {$[9]^{*}$} & This work \\
\hline \hline Max. $V_{\text {bus }}[\mathrm{V}]$ & 680 & 840 & 540 \\
\hline Device & $\mathrm{C} 3 \mathrm{M} 0065100 \mathrm{~K}$ & $\mathrm{C} 3 \mathrm{M} 0075120 \mathrm{~J}$ & $\mathrm{GS66508 \textrm {T }}$ \\
\hline Technology & $\mathrm{SiC}$ & $\mathrm{SiC}$ & $\mathrm{GaN}$ \\
\hline Breakdown Voltage $[\mathrm{V}]$ & 1000 & 1200 & 650 \\
\hline$R_{\text {DS(on) }} @ 25^{\circ} \mathrm{C}[\mathrm{m} \Omega]$ & 65 & 75 & 50 \\
\hline$Q_{g}[\mathrm{nC}]$ & 35 & 51 & 5.8 \\
\hline$E_{\text {oss }} @ \max . V_{\text {bus }}[\mathrm{HJ}]$ & 18 & 25 & 10 \\
\hline$Q_{r r}[\mathrm{nC}]$ & 310 & 220 & 0 \\
\hline FoM1 $=R_{D S(\text { on) }} \cdot Q_{g}$ & $2.28 \mathrm{E}-09$ & $3.83 \mathrm{E}-09$ & $2.90 \mathrm{E}-10$ \\
\hline $\mathrm{E}-\mathrm{FoM}=R_{D S(\text { on })} \cdot E_{\text {oss }}$ & $1.17 \mathrm{E}-06$ & $1.88 \mathrm{E}-06$ & $0.50 \mathrm{E}-06$ \\
\hline
\end{tabular}

${ }^{*}$ The 100-A device used in this reference is replaced with a 30 -A device for the same rated voltage for a better comparison.

range allows for the incorporation of $650-\mathrm{V}$ GaN devices for both the primary and secondary switches, whereas prior art reports higher maximum bus voltages, and accordingly $\mathrm{SiC}$ devices are incorporated for the ac-dc stage and the primary switches in the dc-dc stage. Table I shows a comparison between the device employed in this work and the state-of-theart devices incorporated in prior art. The comparison shows that a GaN device rated for the same current and a lower breakdown voltage has significantly better figures of merit (FoMs) compared to the $\mathrm{SiC}$ counterparts. That can lead to the improvement of the overall system efficiency with the incorporation of $\mathrm{GaN}$ devices in both stages. Furthermore, the GaN device has zero reverse-recovery charge $Q_{r r}$. As a result, the presented work investigates and employs the reverse conduction characteristics for the resonant tank high-frequency current rectification. This simplifies the design and eliminates the need for synchronous driving circuitry or matching networks in the resonant tank. It is noted that this comparison is not intended to be between devices (e.g. GaN vs. SiC), but rather between the different system architectures and control methods. Previous implementations have tended to use a wide $V_{\text {bus }}$ range for the wide load voltage range, which requires the use of $900-\mathrm{V}$ or $1.2-\mathrm{kV}$ devices. In contrast, the converter proposed in this paper limits the range of $V_{b u s}$ (while still allowing a wide variation in output voltage) and so allows the use of $650-\mathrm{V}$ GaN devices. The proposed design can therefore be constructed entirely from $650-\mathrm{V}$ GaN devices, whereas previous designs cannot. The proposed design can be modified to use $650-\mathrm{V}$ SiC or $\mathrm{Si}$ devices, although the switching frequency would likely need to be reduced in this case. Nevertheless, a device rated for lower breakdown voltage will have better FoMs. 


$$
M_{r}=\frac{k \cdot f_{n}{ }^{3}}{\sqrt{\left[Q_{l} \cdot\left(f_{n}{ }^{4} \cdot(1+2 k)-f_{n}{ }^{2} \cdot(2+2 k)+1\right)\right]^{2}+\left[f_{n} \cdot\left(1-f_{n}{ }^{2} \cdot(1+k)\right)\right]^{2}}}
$$

\section{B. Converter Topology}

The CLLC converter schematic is shown in Fig. 3. Halfbridge switch networks are employed for the primary and secondary sides. The switch voltages are confined by the dcbus and battery voltages. Depending on the power flow direction, the inverting half bridge is switched at the switching frequency with $50 \%$ duty cycle and fixed dead time, while the rectifying half bridge operates in reverse conduction throughout the entirety of the switching period. ZVS is achieved at turn-on for the inverting devices at all loads. The resonant tank is designed to offer symmetric operation across both power directions, where the transformer leakage inductance is part of the resonant tank, allowing for the integration of the resonant inductors in the transformer. Equation (2) shows an expression for the resonant tank gain (excluding transformer turns ratio) derived based on the first harmonic approximation (FHA) approach for analyzing resonant converters. The quantities $f_{n}$, $Q_{l}$, and $k$ are the normalized switching frequency, the loaded quality factor, and the ratio between the transformer magnetizing inductance and the primary resonant inductance, respectively. They are defined as follows:

$$
\begin{gathered}
f_{n}=\frac{f_{s}}{f_{r}} \\
Q_{l}=\frac{\sqrt{L_{r p} / C_{r p}}}{R_{r}} \\
k=\frac{L_{m}}{L_{r p}},
\end{gathered}
$$

where $R_{r}$ is the load resistance $R_{l}$ reflected at the rectifier input and referred to the primary side.

$$
\begin{gathered}
f_{r}=\frac{1}{2 \pi \sqrt{L_{r p} \cdot C_{r p}}} \\
R_{r}=\frac{2 n^{2} \cdot R_{l}}{\pi^{2}}
\end{gathered}
$$

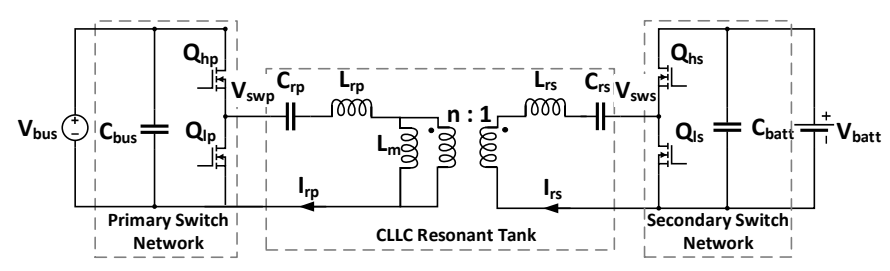

Fig. 3. CLLC converter schematic.

\section{DESIGN \& IMPLEMENTATION}

\section{A. Design Specifications}

Table II lists the specifications for the dc-dc stage design based on the architecture discussed in Section II, where different operational points are identified for the different load modes and power directions. Point A corresponds to the operation at the terminal voltage of the battery low SoC, with the minimum battery voltage of $250 \mathrm{~V}$. Point $\mathrm{B}$ corresponds to the border between the $\mathrm{CC}$ and $\mathrm{CP}$ modes, with a battery voltage of $320 \mathrm{~V}$. Points $\mathrm{C}$ and $\mathrm{D}$ then lie along the $\mathrm{CP}$ charging mode, with point $\mathrm{D}$ corresponding to the terminal voltage at the battery high SoC. On the other hand, points BR-DR represent the reverse power flow in the $\mathrm{V} 2 \mathrm{G}$ mode. The $1-\mathrm{kW}$ power specification targets modular level-2 on-board chargers, where the same design can be scaled for higher power through multiplying of the converter or redesign of the resonant tank. A maximum switching frequency of $500 \mathrm{kHz}$ is chosen for this design, which makes a good tradeoff between the power density and efficiency, considering the range of high frequencies that the state-of-the-art magnetic materials allow for.

\section{B. Resonant Tank Design}

The design goal is to maintain soft-switching operation across the entire charging cycle. The design process starts with the calculation of the minimum needed resonant tank gain.

$$
M_{r_{-} \text {min }}=\frac{V_{\text {batt_min }} \cdot n}{V_{\text {bus_min }}}=0.78
$$

With a specified maximum switching frequency, and choosing a maximum normalized switching frequency of 1.25 , which is not too far from the resonant frequency, ensuring the validity of the FHA approach, the resonant frequency is calculated to

$$
f_{r}=\frac{f_{s_{-} \max }}{f_{n_{-} \text {max }}}=400 \mathrm{kHz}
$$

Following, a preliminary value for $k$ is chosen. The value for the parameter $k$ constitutes a tradeoff between the maximum gain and efficiency. A low $k$ value results in peaking of the resonant tank gain curve below resonance for the same quality factor, providing boost function and extending the inductive mode of operation below the resonant frequency. At the same time, the low $k$ value is achieved with a smaller transformer magnetizing inductance $L_{m}$, which, in turn, results in higher

TABLE II. DESIGN SPECIFICATIONS

\begin{tabular}{c|c|c|c|c|c|c|c}
\hline Power Flow & \multicolumn{4}{|c|}{ Forward (G2V) } & \multicolumn{3}{c}{ Reverse (V2G) } \\
\hline Load Mode & CC & \multicolumn{3}{|c|}{ CP } & \multicolumn{3}{c}{ CP } \\
\hline Point $(i)$ & A & B & C & D & BR & CR & DR \\
\hline \hline$V_{\text {in }}[\mathrm{V}]$ & 380 & 384 & 504 & 540 & 320 & 420 & 450 \\
\hline$V_{\text {out }}[\mathrm{V}]$ & 250 & 320 & 420 & 450 & 384 & 504 & 540 \\
\hline$I_{\text {out }}[\mathrm{A}]$ & 3.13 & 3.13 & 2.38 & 2.22 & 2.6 & 1.98 & 1.85 \\
\hline$P_{\text {out }}[\mathrm{W}]$ & 781.25 & 1000 & 1000 & 1000 & 1000 & 1000 & 1000 \\
\hline
\end{tabular}




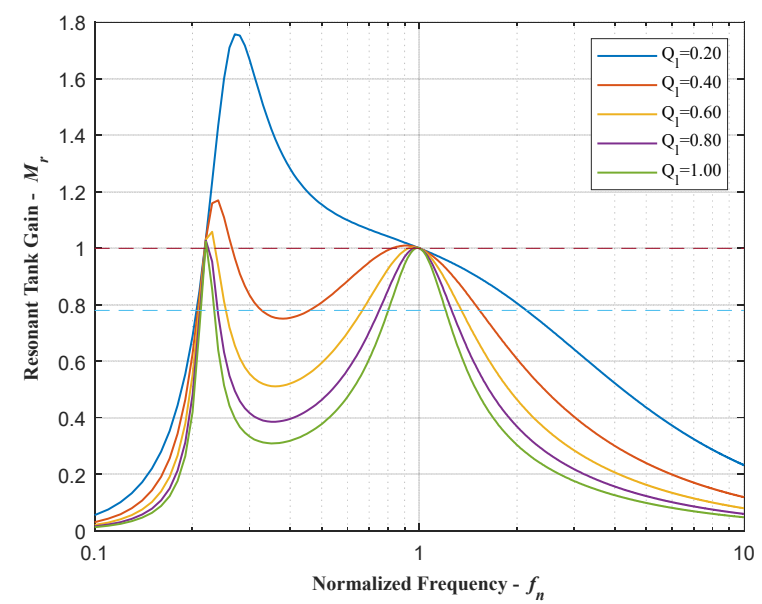

Fig. 4. Resonant tank gain across the normalized switching frequency for different loads for $k=10$

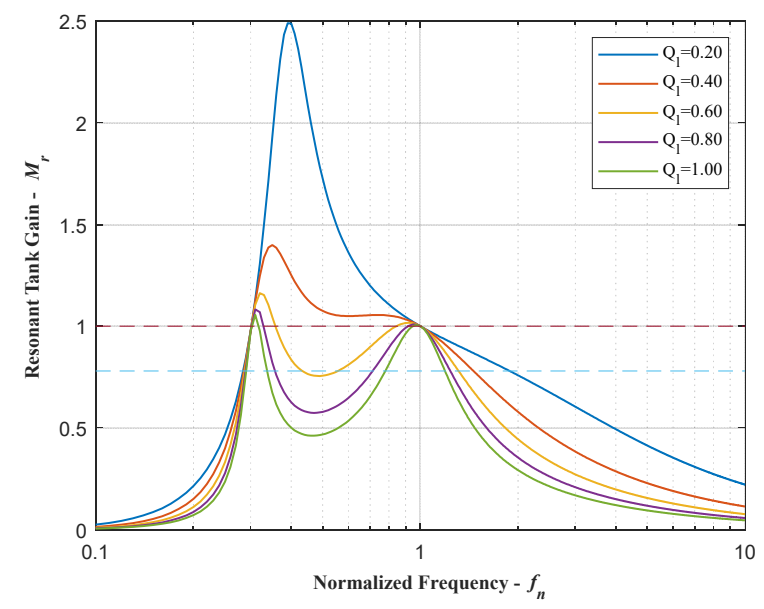

Fig. 5. Resonant tank gain across the normalized switching frequency for different loads for $k=5$.

TABLE III. LOADED QUALITY FACTORS FOR THE MAIN OPERATIONAL POINTS FOR DIFFERENT K VALUES

\begin{tabular}{l|l|l}
\hline$k$ & 10 & 5 \\
\hline \hline$Q_{L A}$ & 0.82 & 0.75 \\
\hline$Q_{L B}$ & 0.64 & 0.59 \\
\hline$Q_{L C}$ & 0.37 & 0.34 \\
\hline$Q_{L D}$ & 0.33 & 0.3 \\
\hline
\end{tabular}

magnetizing current that leads to increased conduction losses. On the other hand, if the $k$ value is made too high, the magnetizing current can be too small to deplete the inverter devices' output capacitances before turn on (for the same dead time), resulting in partial or full loss of ZVS. For the presented architecture, where no boost gain is needed in the resonant tank, the choice of the $k$ value solely depends on the ZVS operation of the converter. The optimal design is the one with the highest $k$ value that helps reduce the magnetizing current to the limit that guarantees ZVS at all conditions with minimized circulating energy. Starting with a value of $k=10$, which allows for easy integration of the resonant tank series inductances into the transformer leakage inductance, (2) is plotted in Matlab against $f_{n}$ for different values of $Q_{l}$, shown in Fig. 4 . The maximum loaded quality factor, respective to point $\mathrm{A}$, is defined by selecting the curve that achieves the required minimum gain $M_{r_{-} \min }$ at the maximum normalized frequency $f_{n_{-} \max }$. Having defined the maximum $Q_{l}$, the corresponding values for the other operational points are calculated as follows.

$$
Q_{l_{\_} i}=\frac{Q_{l \_ \text {max }} \cdot R_{l \_ \text {max }}}{R_{l_{-} i}}
$$

The values are listed in Table III. As the operational points B, $\mathrm{C}$, and $\mathrm{D}$ operate at resonance, ZVS is ensured (by design) by maintaining a lag between the resonant current and switching node voltage at resonance. By checking the respective load curves at $f_{n}=1$, it is observed that achieving ZVS at resonance with $k=10$ is challenging. Accordingly, a design iteration with respect to a lower $k$ value is conducted. Fig. 5 shows the gain function for $k=5$ at the same loads, where higher boost gains are achieved below resonance. A maximum $Q_{l}$ value of 0.75 is defined and the respective values for the other loads are calculated and listed in Table III. Circuit simulations are then conducted for the different operational points for forward and reverse power directions to validate gains and ZVS operation for the different $k$ values. It is found that $k=5$ ensures a wider range of operation with ZVS, leading to a higher efficiency. Following, the resonant tank values are calculated as follows:

$$
\begin{gathered}
L_{r p}=\frac{Q_{l_{-} \max } \cdot R_{r_{-} \max }}{2 \pi f_{r}}=6.96 \mu \mathrm{H} \\
C_{r p}=\frac{1}{2 \pi f_{r} \cdot Q_{l_{-} \max } \cdot R_{r_{-} \max }}=22.7 \mathrm{nF} \\
L_{r s}=\frac{L_{r p}}{n^{2}}=4.84 \mu \mathrm{H} \\
C_{r s}=C_{r p} \cdot n^{2}=32.7 \mathrm{nF} \\
L_{m}=k \cdot L_{r p}=34.8 \mu \mathrm{H}
\end{gathered}
$$

\section{Implementation}

Fig. 6 shows a picture of the implemented prototype, and Table IV lists the bill of material of the presented converter, including the designed and implemented values.

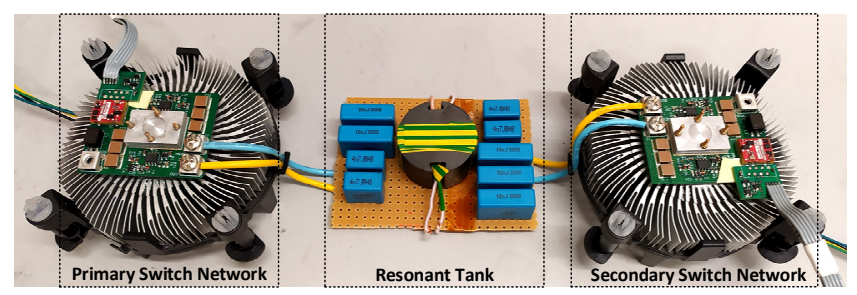

Fig. 6. Prototype picture.

TABLE IV. PROTOTYPE BoM

\begin{tabular}{l|l|l|l}
\hline Component & Design & Prototype & Type \\
\hline \hline$C_{b u s}$ & & $5.64 \mu \mathrm{F}$ & Ceramic \\
\hline$Q_{h p}, Q_{l p}$ & & $2 * \mathrm{GS66508 \textrm {T }}$ & GaN Switches \\
\hline$C_{r p}$ & $22.7 \mathrm{nF}$ & $22.4 \mathrm{nF}$ & Film \\
\hline$C_{r s}$ & $32.7 \mathrm{nF}$ & $32.4 \mathrm{nF}$ & Film \\
\hline$L_{r}$ & $13.92 \mu \mathrm{H}$ & $13.4 \mu \mathrm{H}$ & Custom Design \\
\hline$L_{m}$ & $34.8 \mu \mathrm{H}$ & $21.54 \mu \mathrm{H}$ & Custom Design \\
\hline$C_{\text {batt }}$ & & $5.64 \mu \mathrm{F}$ & Ceramic \\
\hline
\end{tabular}




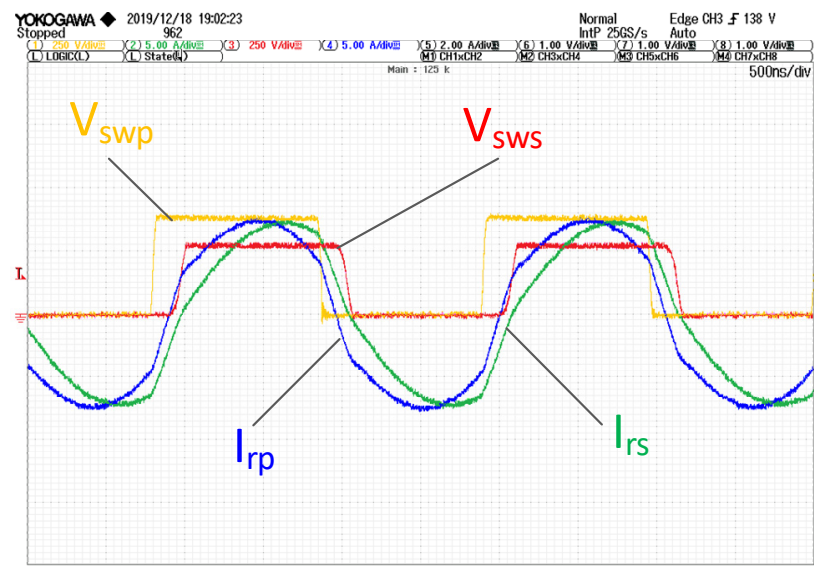

Amplitude(C)
Ampitiduce(c) 380 V
270

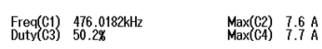

(a)

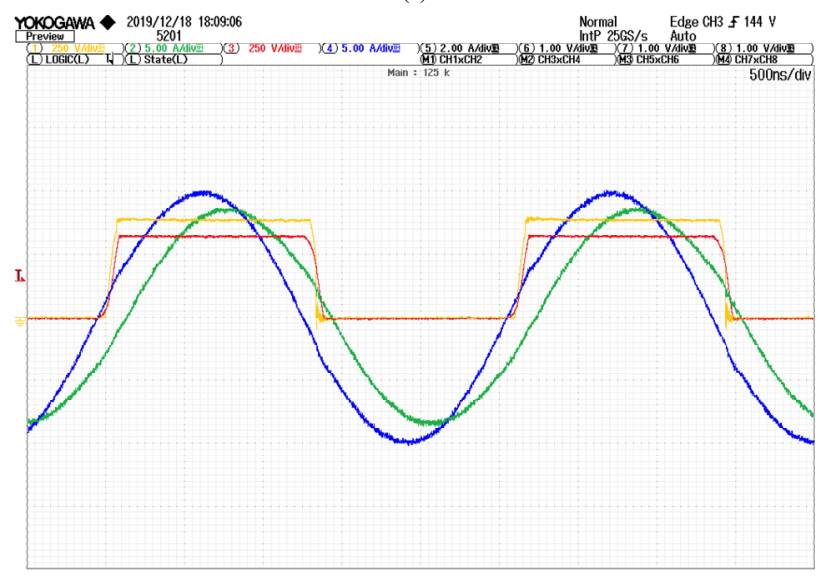
Amplitude(c)
Ampititude(c) 383
$322 \mathrm{~V}$

(b)

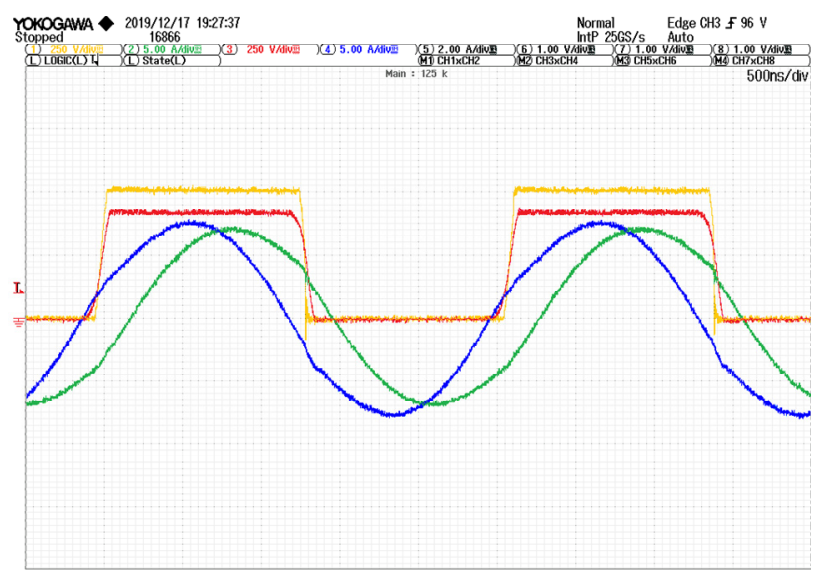

Amplitude(c)
Amplitidec(c) 300 Y
420
Freac(c)
Dutv(v3)
$50.5 \%$
$5 \%$

(c)

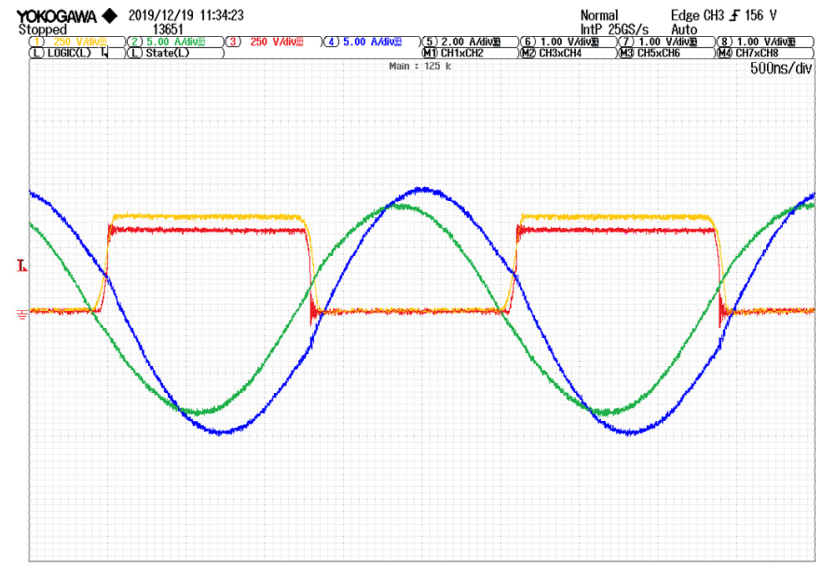

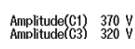

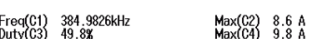

(d)
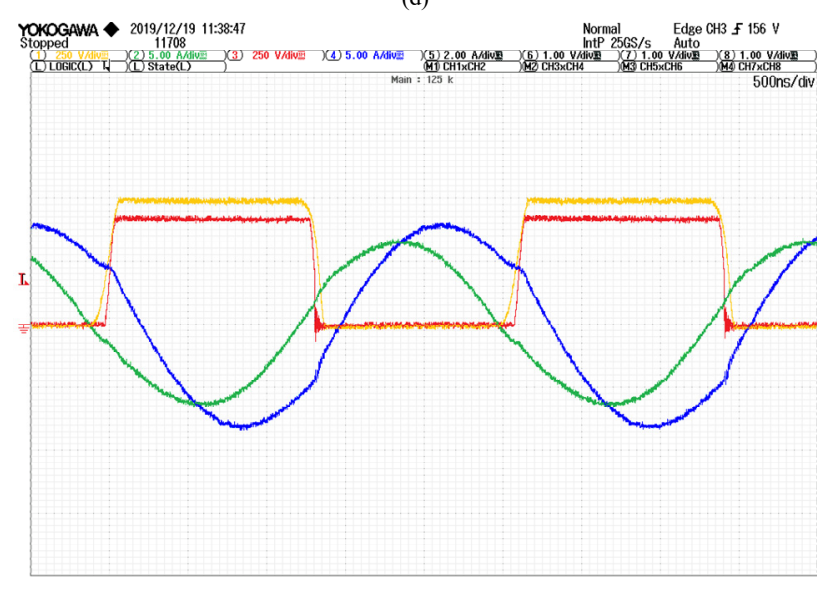

Ampitude(c)
Ampituder(3)
$400 \mathrm{Y}$

(e)
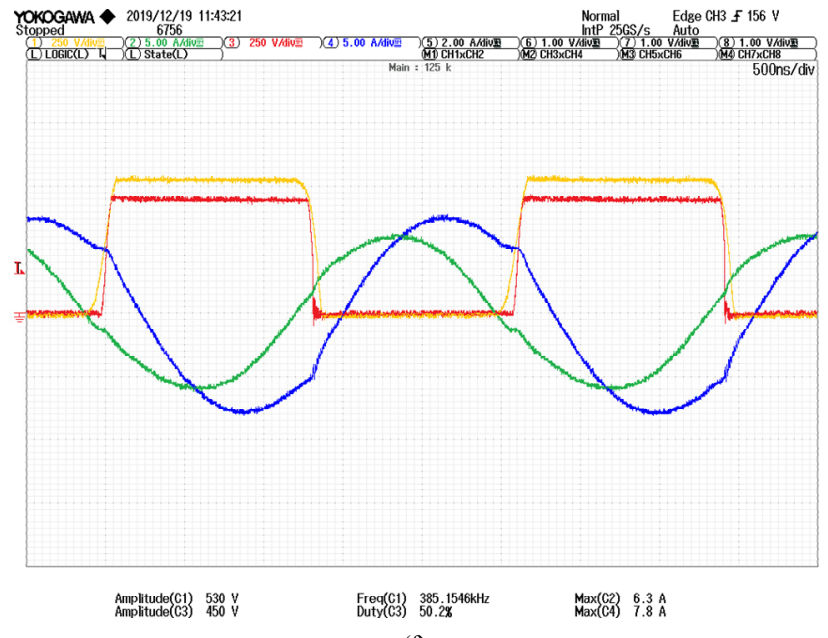

(f)

Fig. 7. Scope captures for different operational points. $\mathrm{CH} 1: V_{S W_{P}} 250 \mathrm{~V} / \mathrm{div}, \mathrm{CH} 2: I_{R_{-}}$at $5 \mathrm{~A} / \mathrm{div}, \mathrm{CH} 3: V_{S W} S$ at $250 \mathrm{~V} / \mathrm{div}$, and $\mathrm{CH} 4: I_{R_{S}}$ at $5 \mathrm{~A} / \mathrm{div}_{\text {. }}$ (a) Point A, (b) point $\mathrm{B}$, (c) point $\mathrm{C}$, (d) point $\mathrm{BR}$, (e) point $\mathrm{CR}$, and (f) point $\mathrm{DR}$. 
For the switching devices, the GaN systems GS66508T devices are incorporated, as they offer the best-in-class figures of merit compared to other commercial devices for the same voltage and power. The 3F46 magnetic material is selected for the transformer core, as it has low losses at the design switching frequency. A P-36/22 core is used and the primary and secondary windings are divided between the core halves and separated, in order to achieve a low coupling coefficient aiding with the integration of the resonant tank series inductances in the transformer leakage inductance, thus saving the space and cost for two additional magnetic devices. The primary winding is realized using 14.5 turns of $140 \times 90 \mu \mathrm{m}$ Litz wire over three layers, while 3 layers of 4 turns each from the same-type wire are used for the secondary winding realization. An air gap of $2.6 \mathrm{~mm}$ is implemented and distributed equally between the inner and outer core legs. A 3D-printed custom bobbin is used to provide $2 \mathrm{~mm}$ separation between the windings to achieve the desired coupling coefficient. The separation also provides clearance of the windings turns around the airgap, which reduces the effect of the fringing flux and the losses associated with it. The transformer small-signal characterization is conducted using an N4L PSM1735 phase sensitive meter with an impedance analyzer interface. The obtained magnetizing inductance is less than that designed for, as shown in Table IV, resulting in an effective $k$ value of about 3.2. With the implemented resonant capacitances, the resonant frequency is measured as $391 \mathrm{kHz}$.

\section{RESULTS}

\section{A. Lab setup}

A thermal camera (Testo 875) continuously monitors the converter operation, and a $350-\mathrm{MHz} 2.5-\mathrm{GS} / \mathrm{s}$ oscilloscope (Yokogawa DLM4038) displays the high-frequency signals. The primary and secondary half bridges' switching nodes are displayed using $150-\mathrm{MHz}$ differential probes (Yokogawa PBDH0150); whereas the currents are displayed using 100-MHz current probes (Agilent N2783A). A low-voltage DC power supply (EA-PS 2342-10 B) supplies the driving circuit, and a 750-V 1500-W power supply (EA-PSI 9750-06 DT) acts as power source. On the other hand, a $750-\mathrm{V} 15-\mathrm{kW}$ bidirectional DC power supply (EA-PSB 9750-60) acts as the load. The source and load connections are interchanged across the converter terminals to test forward and reverse power flows.

\section{B. Measurements}

Fig. 7 shows scope captures for the different operational points discussed in the previous section. It can be observed that active switching takes place on the primary half-bridge switches in subfigures $(\mathrm{a}-\mathrm{c})$, where the secondary half-bridge switches are in reverse conduction for the entirety of the switching period. On the other hand, the roles are changed for the operational points in subfigures (d-f) for which reverse power flow takes place by actively switching the secondary half bridge, while the primary half-bridge switches reverse conduct. The primary and secondary switching nodes voltages are seen to overlap across all figures with operation at resonance, while a phase shift between the two voltages exists in subfigure (a) where the switching frequency is higher than the resonant frequency and a
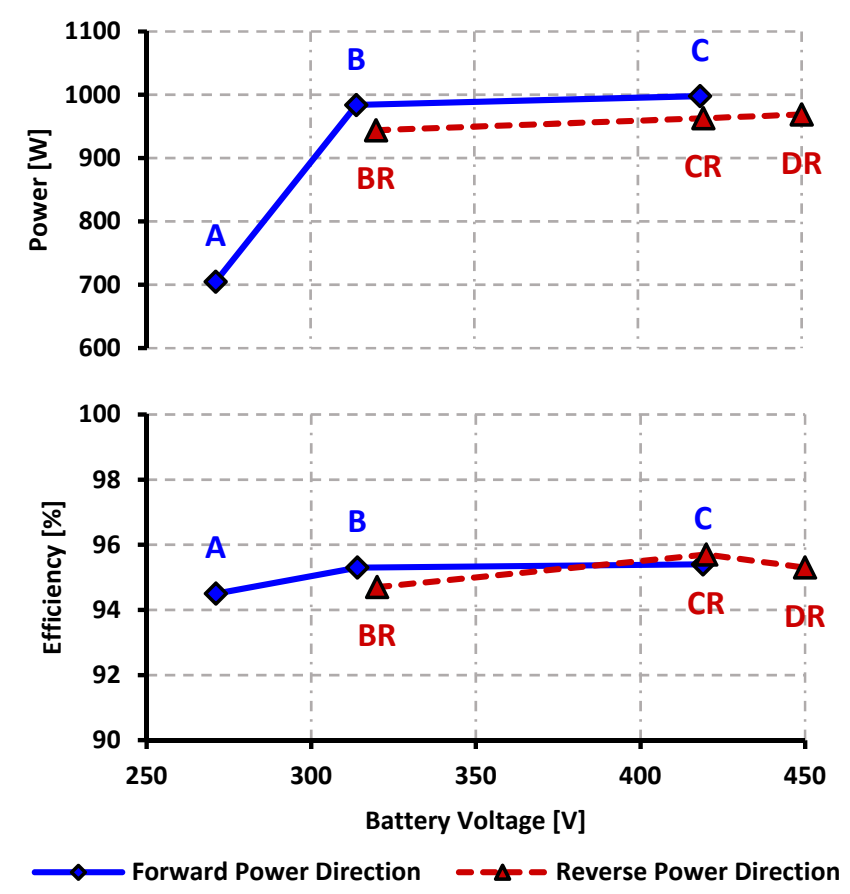

Fig. 8. Obtained power and efficiency across the different operational points.

lower output voltage is achieved. Soft switching is achieved across the different operational points in both power directions.

Fig. 8 shows the obtained output power and efficiency across the different operational points for both power directions. The figure illustrates that an efficiency of up to $95.7 \%$ is obtained, with an average efficiency of $95.2 \%$ across the load range. The gain and power mismatches at several points are due to the differences between designed and implemented values of the resonant tank and can be eliminated with the accurate setting of the switching frequency.

\section{GaN Reverse Conduction Characteristics}

Considering that the $\mathrm{GaN}$ device has zero reverse recovery charge $Q_{r r}$, the loss due to reverse conduction can be estimated as follows. From Fig. 7, it can be seen that the maximum resonant current amplitude takes place on the secondary side at point B, where a sinusoidal current with an amplitude of $10.1 \mathrm{~A}$ is measured. Fig. 9 shows measurement results for the reverse conduction characteristics of the employed GaN device across different temperatures with zero gate-source voltage (obtained using a Keysight B1505A curve tracer). By inspecting the characteristics, the corresponding drain-source voltages for the resonant current values along the sine wave are extracted. The average power loss due to reverse conduction $P_{r c}$ is then calculated as follows.

$$
P_{r c}=\frac{1}{T_{S}} \int_{0}^{T_{S}} I_{D S}(t) \cdot V_{D S}\left(I_{D S}(t)\right) d t=17.3 \mathrm{~W}
$$

Fig. 10 illustrates the converter power loss breakdown at the same operational point. The figure shows that about one third of the total power loss is taking place in the rectifying switches reverse conduction. Accordingly, this design offers simplicity and lower cost by eliminating the need for a complex synchronous driving circuitry or a matching network in the 


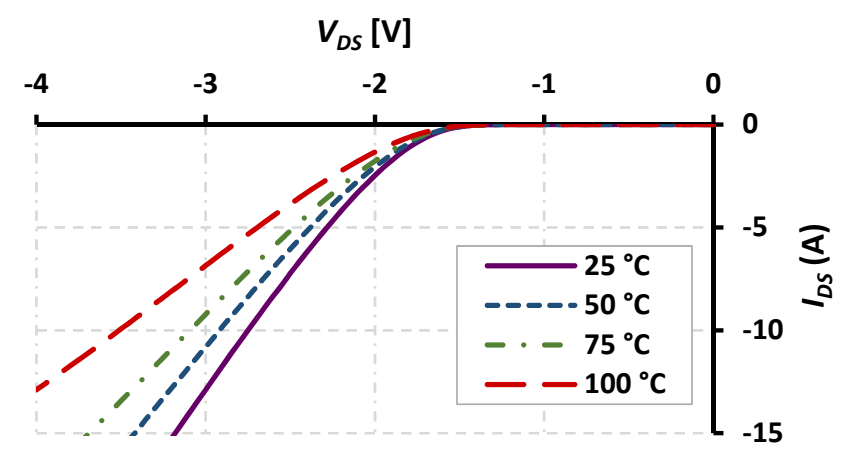

Fig. 9. Measured GS66508T device reverse conduction characteristics across different temperatures.

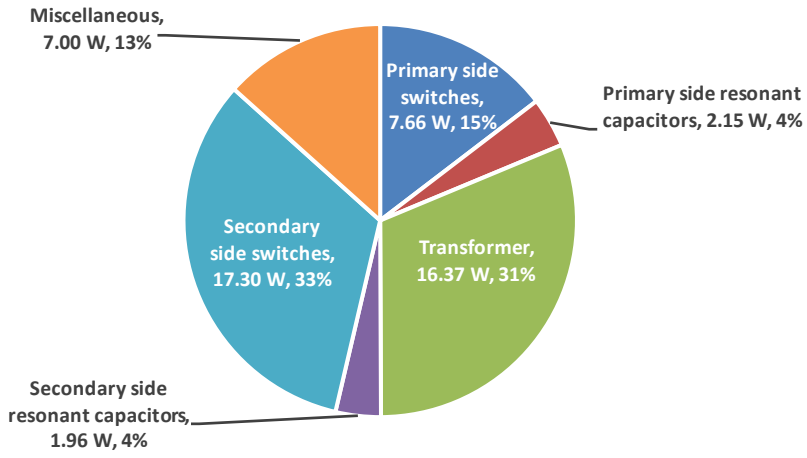

Fig. 10. Converter loss distribution for point B in Watts.

resonant tank at the expense of additional power loss with the reverse conduction of the rectifying devices.

\section{CONCLUSION}

A bidirectional CLLC resonant dc-dc converter for on-board EV charger systems is presented. The proposed architecture allows the converter to operate at resonance for the bidirectional constant-power load range, while frequency modulation is employed for the constant-current load range along the battery charging profile. Compared to prior art that reports a wide bus voltage range and requires the use of $900-\mathrm{V}$ or $1.2-\mathrm{kV}$ devices, this architecture limits the bus voltage range, allowing for the use of $650-\mathrm{V}$ GaN devices for both the primary and secondary switches, and simplifying the requirements on the preceding acdc stage. A high-frequency $1-\mathrm{kW}$ prototype with integrated magnetics is implemented. The prototype operates in ZVS across load range, achieving up to $95.7 \%$ efficiency, with the resonant tank series inductances integrated in the transformer. $\mathrm{GaN}$ reverse-recovery characteristics are exploited for the rectifying switches to eliminate the need for synchronous driving scheme or a matching network in the resonant tank. One third of the total power loss is dissipated in rectification, thus constituting a tradeoff between efficiency and simplicity/cost.

\section{REFERENCES}

[1] A. Khaligh and M. D'Antonio, "Global Trends in High-Power On-Board Chargers for Electric Vehicles," in IEEE Transactions on Vehicular Technology, vol. 68, no. 4, pp. 3306-3324, April 2019.

[2] E. Hoene, G. Deboy, C. R. Sullivan and G. Hurley, "Outlook on Developments in Power Devices and Integration: Recent Investigations and Future Requirements," in IEEE Power Electronics Magazine, vol. 5, no. 1, pp. 28-36, March 2018.

[3] P. He and A. Khaligh, "Comprehensive Analyses and Comparison of 1 kW Isolated DC-DC Converters for Bidirectional EV Charging Systems," in IEEE Transactions on Transportation Electrification, vol. 3, no. 1, pp. 147-156, March 2017.

[4] A. M. Ammar, Y. Nour and A. Knott, "A High-Efficiency 1 MHz 65 W GaN-Based LLC Resonant DC-DC Converter," 2019 IEEE Conference on Power Electronics and Renewable Energy (CPERE), Aswan City, Egypt, 2019, pp. 448-452.

[5] J. Deng, S. Li, S. Hu, C. C. Mi and R. Ma, "Design Methodology of LLC Resonant Converters for Electric Vehicle Battery Chargers," in IEEE Transactions on Vehicular Technology, vol. 63, no. 4, pp. 1581-1592, May 2014.

[6] J. Jung, H. Kim, M. Ryu and J. Baek, "Design Methodology of Bidirectional CLLC Resonant Converter for High-Frequency Isolation of DC Distribution Systems," in IEEE Transactions on Power Electronics, vol. 28, no. 4, pp. 1741-1755, April 2013.

[7] Z. U. Zahid, Z. M. Dalala, R. Chen, B. Chen and J. Lai, "Design of Bidirectional DC-DC Resonant Converter for Vehicle-to-Grid (V2G) Applications," in IEEE Transactions on Transportation Electrification, vol. 1, no. 3, pp. 232-244, Oct. 2015.

[8] 6.6 kW Bi-Directional EV On-Board Charger, Cree Power Applications, Application Note CPWR-AN25, Rev B, July 2018.

[9] B. Li, Q. Li, F. C. Lee, Z. Liu and Y. Yang, "A High-Efficiency HighDensity Wide-Bandgap Device-Based Bidirectional On-Board Charger," in IEEE Journal of Emerging and Selected Topics in Power Electronics, vol. 6, no. 3, pp. 1627-1636, Sept. 2018. 